\title{
LOS MÚLTIPLES USOS \\ DE LA DIVERSIDAD CULTURAL. \\ LA DIVERSIDAD CULTURAL ANTE EL RACISMO, \\ EL DESARROLLO Y LA GLOBALIZACIÓN EN LOS \\ DOCUMENTOS UNESCO
}

\author{
HONORIO M. VELASCO ${ }^{1}$ \\ Universidad Nacional de Educación a Distancia
}

Resumen: Más que el concepto de diversidad cultural interesa el análisis de los usos de ella. En particular resulta relevante el empleo primero débil y luego, firme, casi profuso por parte de instituciones culturales como la UNESCO con numerosos documentos generados para que sirvan de criterio de las políticas culturales de los estados que los suscriben. Se muestra que a lo largo del tiempo la diversidad cultural ha sido empleada para contrarrestar, subvertir, reorientar, resistir fenómenos sociales tan potentes como el racismo, el desarrollo, la globalización, con distinta suerte y muy variados cambios en su concepción.

Palabras Clave: diversidad cultural, racismo, desarrollo, globalización, políticas culturales.

AвsтRACT: We are interested in analyzing the uses of the concept of cultural diversity, more than the concept itself. The use by cultural institutions such as UNESCO, at first weak and later almost profuse, which has generated numerous documents that serve as a criterion for the cultural policies of the states that sign the conventions is particularly relevant. We shall show that, over time, cultural diversity has been used to counteract, subvert, redirect, and resist such powerful social phenomena as racism, development, and globalization, with mixed fortunes and quite varied changes in its conception.

KEYwORDs: cultural diversity, racism, development, globalization, cultural policies.

${ }^{1}$ hvelasco@fsof.uned.es 
En los documentos UNESCO sobre la «diversidad cultural $»^{2}$ se cumple bien la propuesta de $\mathrm{Geertz}^{3}$ de analizar no tanto su concepto cuanto sus usos. Inevitablemente el concepto de «cultura» que conlleva es objeto de reflexión, pero es más la «diversidad» lo que parece invitar a dirigir la atención hacia los usos no tanto porque la noción no requiera mayor reflexión sino porque ha sido principalmente herramienta de trabajo con distintos propósitos. El viejo método comparativo en la Antropología clásica ${ }^{4}$ era su destino principal. La historia de esos usos institucionales se detiene sobre todo en Enciclopedias y Museos. Pero además, la diversidad ha tenido un variado uso social y político no del todo evidente hasta que el concepto antropológico de cultura fue adoptado por instituciones de la política cultural como la UNESCO. La historia de sus documentos ${ }^{5}$ muestra su naturaleza reactiva, es decir, el concepto fue asociado de forma directa con distintos fenómenos sociales y se hizo su propuesta con el fin de contrarrestar, neutralizar o subvertir el fenómeno con el que se relaciona. Igualmente muestra, en segundo término, los diferentes perfiles y por tanto la diferente agrupación de significados en tiempos distintos y para problemas distintos. En un primer momento, el fenómeno complejo y amenazante en el mundo moderno que había que contrarrestar y en la medida de lo posible neutralizar era el racismo. En un segundo tiempo, el fenómeno complejo y amenazante en el mundo moderno no tanto a contrarrestar sino a reorientar y en algún sentido subvertir fue el desarrollo, liderado por la tecnología y medido y gestionado por la economía. En un tercer periodo, el fenómeno cuya complejidad pareció ocupar todo horizonte y que caracteriza a la postmodernidad es la globalización. La diversidad cultural con la que se intentaba neutralizar el racismo trataba de deshacer un determinismo biológico y disolver así las variedades genéticas como caracterizaciones irrelevantes en la explicación de las diferencias entre los grupos humanos que habrían de reformularse más bien en términos de culturas. La diversidad cultural con la que se intentó reorientar el desarrollo también utilizó el código cultural para superar la estrechez de miras del desarrollo economicista y liberarse

2 Este artículo se integra en los trabajos del proyecto I+D, DER2010-18064 «El nuevo orden de la cooperación internacional para la preservación de la diversidad cultural a la luz del Convenio de la UNESCO de 2005. Referencia particular a España».

3 Geertz, C. (1996[1986]). Los usos de la diversidad. Barcelona: Paidos.

${ }^{4}$ Stocking, G. (1982). Race, Culture and Evolution. Chicago: The University of Chicago Press. Stocking, G. (1987). Victorian Anthropology. Berkeley: The University of California Press.

5 Stenou, K. (2004). Unesco and the Issue of Cultural Diversity. Review and strategy. 19462004. París: UNESCO. STENou, K. (2007). L'UNESCO et la question de la diversité culturelle. 1946-2007. Bilan et stratégies. París: UNESCO. Las etapas que se distinguen en estos informes son: cultura y conocimiento, cultura y política, cultura y desarrollo, cultura y democracia y cultura y mundialización. 
de las constricciones del progreso tecnológico proclamando la libertad creativa y celebrando la enorme variedad de respuestas humanas a los problemas de la supervivencia y facilitando el desarrollo sostenible. Más tarde, la diversidad cultural para no quedar engullida por la globalización dio fundamento a la identidad cultural y al pluralismo. En todos los casos la diversidad cultural aparecía como fuerza dinámica enlazada con la evolución de la especie humana y los cambios y transformaciones de las sociedades humanas y como fuerza liberadora para los individuos y los grupos humanos. Los perfiles que adquirió en los distintos momentos son bien diferentes.

\section{Diversidad cultural vs. racismo}

El racismo había sido durante largo tiempo el soporte ideológico de la colonización y de la desigualdad individual y social. La UNESCO elaboró entre sus primeras tareas varias declaraciones sobre la raza. La primera, tras una reunión de expertos que tuvo lugar en París en 1949, se emite en 1950. La segunda «sobre la raza y las diferencias raciales» es de 1951. Otra, en 1964, las "proposiciones sobre los aspectos biológicos de la cuestión racial», aún otra sobre «sobre la raza y los prejuicios raciales» emitida en 1967 y con el mismo nombre otra finalmente en 1978. Los rasgos de la diversidad cultural que se decantan en ellas son:

1. Se propone a las culturas como foco de las diferencias en vez de las razas (y por tanto se traslada el concepto de la diversidad del ámbito de las ciencias naturales al de las ciencias sociales). De forma muy reveladora en la primera declaración se encuentra una cita de Confucio «La naturaleza de los hombres es idéntica, son sus costumbres las que los separan» (Declaración 1950, punto 9).

2. Se desvinculan las diferencias en las culturas de las diferencias percibidas en las razas. Se niega categóricamente que las diferencias genéticas sean causa de las diferencias culturales, y más bien éstas «se explican por la historia cultural de cada grupo (humano)» (Declaración 1950, punto 10). «Los aspectos culturales de los grupos nacionales, religiosos, geográficos, lingüísticos o culturales no tienen ninguna relación genética demostrable con los caracteres propios de la raza» (Declaración 1950, punto 6).

3. Las diferencias físicas no responden sólo a dotaciones hereditarias. Se están modificando constantemente, responden también a mutaciones o a modificaciones accidentales, a la influencia del medio, a las costumbres relativas al matrimonio,... (Declaración 1951, punto 2). La diversidad (se entiende biológica) no es sólo resultado del aislamiento sino también de la hibridación y el 
mestizaje. La diversidad no debe aplicarse sólo a las diferencias entre unos grupos humanos y otros sino también a las diferencias en el seno de los mismos grupos (Declaración 1951, Preámbulo).

4. En el documento de propuestas de 1964, dentro del punto 13 se afirma la igualdad en cuando a las capacidades y potencialidades «biológicas» de los pueblos del mundo para alcanzar cualquier grado de «civilización» y se afirma igualmente que «las diferencias en resultados parecen deberse enteramente a su historia cultural».

5. No hay ninguna razón para fundamentar las desigualdades sociales en las diferencias físicas (Declaración 1964). «Todos los seres humanos nacen libres e iguales en dignidad y en derechos», comienza la Declaración de 1967, reafirmando los Derechos Humanos.

Pero en estas declaraciones no aparece explícita y literalmente formulada la Diversidad Cultural que meramente se muestra como una constatación. La inspiración de todas ellas son, como se advierte, los Derechos Humanos. No obstante, es a Claude Lévi-Strauss, (miembro del comité de sabios de la citada primera Declaración $1950^{6}$, que sin embargo no aparece después como integrante de los comités formados por antropólogos físicos y biólogos) a quien puede atribuirse una inequívoca reflexión sobre el concepto cuya relevancia se enuncia enfáticamente en el texto «Raza e historia» ${ }^{7}:$ «La necesidad de preservar la diversidad de las culturas en un mundo amenazado por la monotonía y la uniformidad, no ha escapado a las instituciones internacionales. Estas también comprenden que para alcanzar esta meta no será suficiente con cuidar de las tradiciones locales y conceder un descanso en los tiempos revueltos. Es el hecho de la diversidad ${ }^{8}$ el que debe salvarse, no el contenido histórico que le ha dado cada época y que ninguna podría perpetuar más allá de sí misma». Es indispensable advertir que la diversidad está invocada aquí a propósito de la «supervivencia biológica y cultural» de la humanidad y del «progreso que no sólo se explica por medio de los cambios

${ }^{6}$ Los miembros del comité de expertos eran Ernest Beaglehole, Juan Comas, L. A. Costa Pinto, E. Franklin Frazier, Morris Ginsberg, Humayun Kabir, C. Lévi-Strauss y M. F. Ashley Montagu.

7 Este escrito es de 1952 y aparece en un libro colectivo con vocación divulgadora e intencionadamente proyectado para combatir al racismo: La question raciale davant la science moderne. París: UNESCO. En el mismo volumen hay también un capítulo de Michel LeIRIs, «Raza y cultura» que está encabezado por la cita de Confucio ya mencionada. Luego ha sido reproducido profusamente. También en Velasco, H. M. (comp.) (2010). Lecturas de Antropología Social y Cultural. La cultura y las culturas. Madrid: UNED, pp. 67-107.

${ }^{8}$ Subrayado del autor. 
tecnológicos», pues, «para progresar es preciso que los hombres colaboren y en el curso de esa colaboración reconocerán gradualmente las aportaciones cuya diversidad inicial era precisamente lo que hacía su colaboración fecunda y necesaria»?

El apartado 2 de esta obra está dedicado a la presentación y explicación antropológica de la diversidad de las culturas. Por supuesto, el punto de partida es la desvinculación entre raza y cultura — antes mencionada-, una cuestión que entonces era ineludible pues el racismo reducía inaceptablemente la diversidad a una injustificable desigualdad. Era obligado mostrar que la evolución de las culturas no era debida a las dotaciones innatas, que miembros de la misma raza pueden haber desarrollado culturas muy distintas y que en la humanidad está constatada la existencia de muchísimas culturas, mientras que el número de razas es bien reducido. Sin que esto impida afirmar la estrecha relación entre los procesos de la diversidad biológica y los de la diversidad cultural, que el propio Lévi-Strauss mantiene como paralelos.

Es bien evidente que la fuerte instalación del racismo exigió sucesivas declaraciones cuya intención, como se ha señalado repetidamente, era anular completamente su anclaje biologicista mediante pronunciamientos de los científicos que desmantelaron los argumentos racistas con datos y demostraciones empíricas y mostraron al mundo que la ciencia no servía ni debía servir para justificar una desigualdad social. Ciertamente los pronunciamientos de los científicos no fueron suficientes y prueba de ello es la reiterada elaboración de Declaraciones a lo largo de treinta años. Aquellas primeras reflexiones de Lévi-Strauss en 1952 apenas tuvieron eco y de nuevo en 1971 en "Raza y cultura ${ }^{10}$ hubo de retomar la cuestión de la diversidad cultural, otra vez comenzando por desmantelar su vinculación con la raza. Si era necesario remarcarlo es porque se había extendido enormemente la opinión de Gobineau, sin embargo expresada como certeza, de que las razas eran las condiciones a priori de la diversidad de las culturas históricas. En el trabajo de 1952 expuso algunas de las ideas básicas que han formado ya cuerpo en la noción de «diversidad cultural». Especialmente aquellas que dan fundamento al principio primario de la diversidad cultural: «el de igual dignidad y respeto de todas las culturas» (principio rector n. ${ }^{\circ} 3$ en la Convención de 2005). Principio que no sólo contrarresta al racismo sino también —como

9 Con estas palabras LÉvi-STrauss hace un guiño a la referencia a la «diversidad fecunda» que aparece en la Constitución de la UNESCO.

10 Lévi-Strauss, C. (1971). "Race et culture». C. Rev. Int. Sc. Soc., vol. XX, n.o 4. La Revue Internationale des Sciences Sociales es una revista editada por la UNESCO desde 1949. 
bien supo ver Lévi-Strauss - al etnocentrismo, es decir, que no sólo es injustificable afirmar que sólo las razas superiores tienen cultura o una cultura superior (una civilización) a las demás sino que también es injustificable afirmar que sólo la cultura propia es cultura o una cultura superior a las demás. Si se quiere este principio presupone un reconocimiento, el de la diversidad, que se suele tomar como una constatación, un hecho (Informe mundial 2010). Pero no debería olvidarse que este hecho no se impone por sí mismo y su negación no se debe simplemente a "desconocimiento", sino que para reconocerlo es necesario desprenderse de los prejuicios.

Además de desprenderse de ellos para llegar al principio de la igual dignidad de las culturas, Lévi-Strauss desarrolló su argumento en dos direcciones, cada una de ellas ha tenido posterior repercusión. Por un lado, afronta el doble rostro de la diversidad, pues tanto se percibe con rotundidad con sus innumerables formas de vivir, prácticas, creencias, tradiciones, etc. de las distintas sociedades humanas, como se percibe con recelo al considerarla una potencial amenaza a las propias formas y tradiciones o incluso un obstáculo al entendimiento entre los pueblos. Por otro lado, analiza la intención de suprimir la diversidad de las culturas que se adivina bajo un esquema pseudo-evolucionista pues de esa manera podría decirse que la diversidad tan sólo es aparente, se trataría de diferentes estadios o etapas de desarrollo de la humanidad. Pero al plantearla en el marco adecuado, el que proporciona la idea de progreso, la diversidad no sólo no se suprime sino que se realza, pues es con ella y con las colaboraciones y alianzas entre las culturas con las que ha sido posible el progreso de la humanidad. «Querer evaluar contribuciones culturales cargadas de una historia milenaria y de todo el peso de los pensamientos, de los sufrimientos, de los deseos y del afán de los hombres que las trajeron a la existencia, remitiéndolos exclusivamente al patrón de una civilización mundial que es aún una forma vacía, sería empobrecerlas singularmente, vaciarlas de su sustancia y quedarse sólo con un cuerpo descarnado» (L-S. ed.cit. p.102). Sólo al mostrar las múltiples aportaciones de las distintas culturas, las occidentales y las orientales, las africanas o las americanas y al ir mostrando cómo esas aportaciones han pasado de unas a otras sociedades, tal y como se han producido en la historia, es posible dar evidencia de la igual dignidad de las culturas. Y aún más, de la diversidad sustrato de la creatividad.

\section{Diversidad cultural $v s$. Desarrollo}

Sin embargo resulta difícil —y presumiblemente innecesario- buscar alguna conexión o esperar coherencia entre estos planteamientos y los que se perciben 
claramente o se entrevén en los documentos principales UNESCO de la época. Puesto que han sido citados como "antecedentes» por la Declaración Universal de 2001, habría que mencionar el Acuerdo de Florencia de 1950 y su Protocolo de Nairobi de 1976, la Convención Universal sobre Derecho de Autor de 1952, la Declaración de los Principios de la Cooperación Cultural de 1966, la Convención sobre las Medidas que deben adoptarse para prohibir e impedir la Importación, la Exportación y la Transferencia de Propiedad Ilícitas de Bienes Culturales 1970. Salvo en uno, en los demás no se invoca el concepto de diversidad cultural y, además, propiamente el concepto de cultura con el que todos ellos operan no tiene la misma denotación que el concepto de cultura al que se alude en las Declaraciones de racismo ni el reelaborado en los trabajos de LéviStrauss. Este concepto de cultura encuentra en ellos, por ejemplo, en el Acuerdo de Florencia o en la Convención de Derecho de Autor o en la Convención sobre el tráfico ilícito de bienes culturales, referentes explícitos, listados de elementos que dan concreción al concepto, y que responden a su identificación con el arte, la educación formal y la ciencia. En relación con todos estos documentos se diría que la diversidad no era entendida como aspecto esencial de la cultura, toda vez que la cultura se tomaba en su pleno sentido humanístico integrada por el arte, la educación y la ciencia, y por tanto universal.

Sin embargo, en la Declaración de Principios de la Cooperación Cultural de 1966, el artículo primero enunciaba: «1. Toda cultura tiene una dignidad y un valor que deben ser respetados y protegidos. 2. Todo pueblo tiene el derecho y el deber de desarrollar su cultura. 3. En su fecunda variedad, en su diversidad y por la influencia recíproca que ejercen unas sobre otras, todas las culturas forman parte del patrimonio común de la humanidad.» Si bien el artículo $4^{\circ}$ al mencionar los contenidos de la cooperación cultural en concreto se refiere a «las artes y las letras, los progresos de la ciencia». Este texto resume bien las tensiones de significado que se producían en el concepto de «diversidad». En él se encuentra, por un lado, y esta vez con el objetivo de fundamentar la cooperación, el enunciado del principio primario de la diversidad cultural, con el añadido de la valoración de "patrimonio común de la humanidad». En uno de los Considerandos se habla literalmente de "los modos de vida, los usos y costumbres de los pueblos», y de que la ignorancia de ellos es un obstáculo para la amistad entre las naciones, la cooperación pacífica y el progreso de la humanidad. Si bien el párrafo final de los Considerandos identifica el contenido central de la Declaración con «la cooperación de las naciones del mundo en las esferas de la educación, la ciencia y la cultura». Como no es posible desligar estos textos de los contextos políticos en los que fueron elaborados se evidencian otras tensiones 
que presumiblemente dejan huella en las que aquí se manifiestan. La diversidad reconocible es aquella que deja incólume la soberanía de los estados, aunque su designación aquí sea la de "pueblos» $\mathrm{o}$ "naciones» ${ }^{11}$. Parece haberse generado un doble discurso que en este periodo se hace visible: uno es aquel que fluye en los documentos para combatir el racismo y el otro el de los documentos de la cooperación cultural. Uno asume el concepto antropológico de cultura, el otro el concepto humanístico. Uno otorga perfil propio a las culturas, el otro redibuja el perfil de las culturas en los contornos de los estados. Y no debiera sorprender que ambos liguen la diversidad cultural con el progreso, aunque de diverso modo. El primero - aunque propiamente se trata de palabras de Lévi-Strauss - se encabalga a él para que en el nombre de una civilización mundial no se cometa la torpeza de desdeñar las incontables contribuciones culturales de las sociedades humanas, el segundo estrictamente no hablaba de diversidad, hablaba más bien de soberanía ${ }^{12}$. Este doble discurso se acabará instalando en el conjunto de las instituciones internacionales, con la matización de que en las instituciones no estrictamente culturales predominaba el segundo (tal y como se evidencia en los acuerdos GATTM y en la OMC) y en aquellas en las que se trasegaba con el primero la diversidad cultural sólo se invocaba explícitamente si y solo si también se había adoptado el concepto antropológico de cultura.

Como muestra se puede acudir a otra serie de pronunciamientos de la UNESCO, la Convención del Patrimonio Mundial Cultural y Natural de 1972, la Recomendación sobre la condición del artista de 1980 y la Recomendación de la salvaguardia de la cultura tradicional y el folklore de 1989, también mencionados como antecedentes de la Declaración de 2001, en los cuales el concepto de diversidad cultural tampoco está propiamente tematizado. En la Convención de Patrimonio Mundial de 1972 no se halla ninguna referencia a él y se hace evidente que en esta Convención la extensión del concepto de cultura está limitada al arte y a la historia (y en paralelo el patrimonio natural). En la Recomendación sobre la condición del artista de 1980 no está explícito pero algunas referencias a la «identidad cultural» y especialmente para referirse a las artes tradicionales permiten entender que es a través de ellas como se tematiza el de diversidad. Y en la Recomendación de la cultura popular de 1989 se encuentra una mención directa

${ }^{11}$ Los análisis internos confirman en este periodo la identificación de cultura con la producción artística y con la información histórica y la diversidad cultural se somete a la cláusula de reserva de jurisdicción doméstica que estaba en la Constitución de la UNESCO, STEnou, $\mathrm{K}$. (2004), p.5.

12 En esta misma línea Stenou, K. (2004) y Barreiro, B. (2011). 
en el Apartado D, asociándola al modo antropológico con las «diferentes visiones del mundo» y numerosas alusiones a la «identidad cultural». El documento sobre la condición del artista muestra por un lado que la identidad cultural se invoca cuando se habla de las artes tradicionales (Considerandos), del patrimonio espiritual de las diferentes sociedades (principio rector 1), y de la cultura tradicional y el folklore (apt.4, punto 2 y ap.7, b), pero por otro lado no se invoca cuando se habla de la libertad de la expresión artística, la creatividad, la evolución de las sociedades, el desarrollo del arte y de la cultura y tampoco cuando se reconoce el arte como «una forma universal de expresión y comunicación y como denominador común de las diferencias étnicas, religiosas o culturales» (principio rector 1).

La emergencia de la reflexión sobre la relación entre cultura y desarrollo no fue abrupta ni tampoco autónoma o desligada de otras líneas. En el periodo de la descolonización con la formación de numerosos estados se fue también incrementando la visibilidad de las minorías dentro de ellos, mientras el desarrollo y sus grados se convertían en otra fuente de desigualdad, no del todo nueva pues venía anticipada por las anteriores. La serie de Conferencias intergubernamentales sobre políticas culturales (Venecia, Helsinki, Yogyakarta, Accra, Bogotá y México) en sus declaraciones y resoluciones recoge numerosos pronunciamientos sobre el desarrollo y la cultura cuya síntesis se formaliza en México 1982 en los puntos 10 a 16 de la Declaración:

«10. La cultura constituye una dimensión fundamental del proceso de desarrollo y contribuye al crecimiento, se ha concebido frecuentemente en términos cuantitativos, sin tomar en cuenta su necesaria dimensión cualitativa, es decir, la satisfacción de las aspiraciones espirituales y culturales del hombre. El desarrollo auténtico persigue el bienestar y la satisfacción constante de cada uno y de todos.

11. Es indispensable humanizar el desarrollo; su fin último es la persona en su dignidad individual y en su responsabilidad social. El desarrollo supone la capacidad de cada individuo y de cada pueblo para informarse, aprender y comunicar sus experiencias.

12. Proporcionar a todos los hombres la oportunidad de realizar un mejor destino supone ajustar permanentemente el ritmo del desarrollo.

13. Un número cada vez mayor de mujeres y de hombres desean un mundo mejor. No sólo persiguen la satisfacción de las necesidades fundamentales, sino el desarrollo del ser humano, su bienestar y su posibilidad de convivencia solidaria con todos los pueblos. Su objetivo no es la producción, 
la ganancia o el consumo per se, sino su plena realización individual y colectiva, y la preservación de la naturaleza.

14. El hombre es el principio y el fin del desarrollo.

15. Toda política cultural debe rescatar el sentido profundo y humano del desarrollo. Se requieren nuevos modelos y es en el ámbito de la cultura y de la educación en donde han de encontrarse.

16. Sólo puede asegurarse un desarrollo equilibrado mediante la integración de los factores culturales en las estrategias para alcanzarlo; en consecuencia, tales estrategias deberían tomar en cuenta siempre la dimensión histórica, social y cultural de cada sociedad.»

Es claro que se asumían aquí las tesis del desarrollo humano en la línea de las aportaciones críticas de Amartya Sen y de los trabajos del Programa de Naciones Unidas para el Desarrollo (PNUD), creado en 1965. La definición de desarrollo humano que el PNUD ha incluido en sus informes, contiene de partida una crítica a la focalización de los objetivos economicistas, a las metodologías cuantitativistas y al utilitarismo como filosofía moral. Mientras que reafirma que «el objetivo básico del desarrollo es crear un ambiente propicio para que los seres humanos disfruten de una vida prolongada, saludable y creativa» (Informe 1990) y como principio lo expuesto en el punto 14 anterior: «El hombre es el principio y fin del desarrollo». Los índices del desarrollo por tanto habrían de reformularse en otros términos que el crecimiento económico, los recursos materiales a disposición o el incremento de la dotación tecnológica y el avance científico-técnico, que se expresan cuantitativamente y de hecho responden al utilitarismo como guía de la vida humana. Los incrementos en ingresos o en riqueza no se buscan por sí mismos sino como medios para alcanzar otras metas. Al redefinir entonces el desarrollo como humano se situó el fin principal en el ser humano como tal, no sólo en el bienestar humano y se propusieron otros índices y en definitiva otro modelo de desarrollo. En la Declaración de la Conferencia Intergubernamental de México se subraya que la cultura es una dimensión fundamental del desarrollo, si bien englobada en lo que los Informes del PNUD destacaban insistentemente: su definición humana. En síntesis:

a. El desarrollo es un proceso por el cual se amplían las oportunidades del ser humano.

b. Las tres oportunidades más esenciales son: disfrutar de una vida prolongada y saludable (índice de esperanza de vida), adquirir conocimientos (índice de alfabetización), tener acceso a los recursos necesarios para alcanzar un nivel de vida decente (índice de ingresos per cápita en relación con PIB real). 
c. Otras oportunidades muy valoradas: libertad política, económica y social, que permita la creatividad, el respeto a uno mismo y las garantías de los derechos humanos.

d. El desarrollo humano consiste en la formación de capacidades (salud, conocimientos y destrezas) y también en el empleo adecuado de ellas.

e. No se centra sólo en la satisfacción de las necesidades básicas y el bienestar social de cada ser humano como beneficiario, sino como partícipe y no sólo en la distribución de bienes y servicios sino en la disponibilidad de oportunidades, en la expansión y uso de las capacidades.

Fundamentalmente se constata que el sujeto del desarrollo humano son los individuos, sus necesidades, sus capacidades, sus logros. Y los índices del desarrollo humano se proporcionan para los estados. El PNUD es bien consciente de que las medidas de desarrollo son promedios por lo que ocultan la divergencia interna entre los grupos sociales de los estados, por ejemplo entre hombres y mujeres en relación con la alfabetización, y de que las medidas de las libertades, seguridad personal, respeto a uno mismo, etc. tienen una gran dificultad en concretarse en cantidades específicas. Los índices son ofrecidos en términos cuantitativos, pero por otro lado no se renuncia propiamente a la metodología cualitativa. Los números tienen sobre todo propósitos comparativos y en todo caso son acompañados de explicaciones y consideraciones que refuerzan la condición humana.

La cultura está sin duda introducida plenamente en la definición de desarrollo humano y está explícitamente referida en uno de los índices, el que recoge la adquisición de conocimientos siendo el seleccionado la alfabetización. Este dato y las continuas menciones a la actividad cultural, a las capacidades y conocimientos están en plena coherencia con la configuración de los sujetos del desarrollo humano en tanto que individuos. Sin bien agrupados o más bien englobados en unidades comparadas que son los variados países del mundo, los estados.

En el mismo sentido los puntos antes citados de la Declaración de México mantienen los mismos postulados sobre el carácter de lo humano y a la vez que se llena de contenido con la cultura se predica ésta de los sujetos individuales. Sin embargo, es este mismo documento el que en sus párrafos iniciales presenta el concepto de cultura como

«el conjunto de los rasgos distintivos, espirituales y materiales, intelectuales y afectivos que caracterizan a una sociedad o un grupo social. Ella engloba, además 
de las artes y las letras, los modos de vida, los derechos fundamentales del ser humano, los sistemas de valores, las tradiciones y las creencias».

Es decir, introduce el sentido antropológico que no sólo amplía el concepto hasta incluir los modos de vida, etc., sino que establece como su sujeto las sociedades, los grupos sociales. Y del mismo modo el apartado 1 de Identidad cultural con los puntos 1 al 9 adopta ese concepto. Ambos apartados en secuencia de continuidad muestran una cierta disociación en los contenidos de significado que llenan el concepto de cultura, el primero el dedicado a Identidad cultural opera con él en el sentido antropológico, el segundo el dedicado a Cultura y Desarrollo opera con él en el sentido humanístico. El primero habla de «cada cultura» en modo particular, el segundo de "la cultura» en modo universal. El primero sitúa en escena como protagonistas a los pueblos, el segundo al ser humano individual. Los contenidos del segundo ya han sido expuestos anteriormente por lo que a continuación se exponen en síntesis los del primero:

- desglosa los perfiles de relevancia que la cultura tiene para los pueblos como constitutiva de identidad es decir, como configuración única e irremplazable (Punto 1),

- como proceso de liberación (Punto 2),

- como fuerza dinamizadora (Punto 3), y

- a la vez con él se valora lo que las culturas aportan al patrimonio común de la humanidad (Punto 4),

- lo que importa el respeto y reconocimiento de las minorías culturales (Punto 8) y

- la capacidad de diálogo y la necesidad del pluralismo cultural (Punto 6).

En suma, es aquí en donde de manera más explícita que en ningún otro documento internacional anterior se encuentra la introducción conceptual de la diversidad cultural (indisociable de la Identidad Cultural, se dice en el Punto 5) acompañada por el enunciado de su principio primario, el de la igualdad y dignidad de las culturas (Punto 9).

Este ejemplo paradigmático de doble discurso permite constatar por un lado que la reorientación del desarrollo se hizo fundamentalmente con valores universales y por tanto bajo el amparo de una ética que tenía como soporte al ser humano. Mientras que por otro lado había emergido un nuevo planteamiento en las políticas culturales en el que el principio de soberanía se recluía a la trastienda administrativa al tiempo que ocupaban la tribuna pública la Identidad Cultural y con ella la Diversidad Cultural. Leídos en secuencia los dos apartados de la 
Declaración de México 1982 parece que vincularan también la Identidad y la Diversidad Cultural con el Desarrollo, pero se aprecia claramente en el resto del documento que no hay tal, sólo una breve mención al «desarrollo equilibrado» en el Punto 16 parece mantener ese vínculo. Con exclusión del apartado dedicado a Patrimonio Cultural y en el que no hay tampoco vinculación expresada de éste con el desarrollo (Puntos 23 al 26), todos los demás en los que de forma muy frecuente se vuelve sobre la noción de desarrollo remiten una y otra vez al valor central de lo humano y al concepto humanístico de cultura sin mención alguna de la Identidad y la Diversidad Cultural.

En otros ámbitos se estaba produciendo el debate sobre la excepción cultu$\mathrm{ral}^{13}$ en los que pueden encontrarse algunos paralelismos dignos de ser destacados. Tras las grandes guerras mundiales, la modernización no sólo está ligada al desarrollo sino también y especialmente a la libre circulación de mercancías y la liberalización del comercio internacional (añadiendo a las mercancías los servicios) finalmente corporalizadas en la OMC, cuyos tratados se alzan sobre las normativas proteccionistas de los estados obligándose además a mantenerlos activos constantemente por medio de rondas de negociaciones como la Ronda Uruguay y otras. El desarrollo y la ilimitada extensión del mercado conllevan un predominio de los valores mercantilistas y de su terminología objetivista frente a los cuales pronto aparecen islas de salvedad, excepciones, especificidades, que plantean algunos estados para frenar el flujo de productos exteriores con la intención en principio de proteger los propios. Particularmente era el caso de las mercancías y servicios culturales, si bien es necesario advertir que antes de que se invocara aquí el concepto de cultura como caracterización general se concretaba la cuestión en los productos cinematográficos y del sector audiovisual ${ }^{14}$. Cuánto de significativo tenga el que haya sido el cine y el audiovisual el elemento cultural más sensible a la voraz asimilación mercantilista depende en realidad del contexto en el que se fue agitando el conflicto de intereses, más que de la relevancia que pueda otorgárseles en la cultura de la modernidad. En forma paralela a la reorientación que se pretendió dar al desarrollo subrayando lo humano frente al predominio economicista y tecnológico, al libre comercio se le presentó la excepción cultural desafiando al predominio mercantilista. Su lema: la cultura es algo más que una mercancía. No sólo porque puede ser también un servicio — tal y como enseguida fue objeto de consideración en el GATTS — sino porque con ello se

13 Espléndidamente estudiados por Prieto, J. (2005) y por Barreiro, B. (2011).

${ }_{14}$ En el GATT se menciona en realidad el cine y el patrimonio cultural (concretado en bienes artísticos, históricos o arqueológicos). 
pretendía subrayar que no podían ser reducidos su valores a los mercantiles sino que tendría que marcarse no menos en términos de goce estético, de respuesta a necesidades espirituales, de simbolismo o de representación de identidad. Y no es que en los debates se hiciera especial esfuerzo en profundizar en su naturaleza sino en lo que importaba en cuanto al marco general de libre comercio por lo que descubre de sus desequilibrios entre países con alta concentración de industrias culturales y otros en los que es más reducida o inexistente. El predominio en la dirección de los movimientos comerciales de los primeros a los segundos y la incapacidad de éstos de contrarrestar esos flujos o incluso de mantenerse en los territorios propios es lo que la invocación a la cultura trata de amortiguar justificando medidas restrictivas que se entienden como proteccionistas. La excepción cultural antes de que fuera subsumida y reformulada como diversidad cultural es reveladora del papel que la modernidad ha otorgado a la cultura en hacer aflorar sus contradicciones.

El otro flanco de la crítica a la teoría del desarrollo se mostró especialmente eficaz, pues logró replantear y redefinir su ritmo, su intensidad e incluso su dirección. Desde la biología y más concretamente desde la ecología y como acontecimiento de su mayor expresión desde la Cumbre de Río, la teoría del desarrollo ha recibido también el impacto reformador de la cultura en un sentido un tanto paradójico, si se recuerda que bajo el paradigma estructuralista se postulaba la confrontación entre naturaleza y cultura. Pareciera más bien que desde el campo de los estudios de la naturaleza (en realidad bajo el paradigma sistémico) se trataba de enmendar a la cultura o más bien a la civilización que había encumbrado a la especie humana a costa de poner en peligro el planeta. La cumbre de Rio fue la tumba de la idea decimonónica del Progreso. El Informe Brundland acometió una crítica profunda a la teoría del desarrollo al encararle con el futuro («Nuestro futuro común» era su título, 1987). Los principales fallos del desarrollo se podían encontrar fácilmente: el incremento de los números absolutos de gente hambrienta, el incremento de personas que no saben leer ni escribir, el incremento de personas que no disponen de agua sana o de viviendas saludables, y el creciente distanciamiento entre países ricos y pobres en una tendencia que no parece posible invertir. A los que hay que añadir las amenazas que van a alterar el planeta y las vidas de muchas especies, tales como la desertificación, la pérdida de los bosques, el calentamiento global, y otras consecuencias de los gases industriales en salud, ruptura de la cadena alimenticia en los océanos, sustancias tóxicas en la cadena alimenticia humana,...(párrafos 6 y 7). Y postula tanto el abandono del criterio del crecimiento económico para los países en desarrollo, 
como una nueva dirección, la del desarrollo sostenible, y para todos países, los que están en desarrollo y los industriales.

Las nociones básicas del concepto de desarrollo sostenible ya estaban enunciadas en los trabajos de la Comisión Mundial de Medio Ambiente y Desarrollo en 1982. La primera de ellas es clave y afirma que el medio ambiente no puede ser entendido aisladamente, no separado de las acciones humanas, de sus necesidades y de sus ambiciones y del mismo modo el desarrollo no puede ser restringido al enriquecimiento de las naciones. Medio ambiente y desarrollo están estrecha e indefectiblemente entrelazados. La segunda recoge la constatación de que el nivel de desarrollo que han alcanzado algunos países no es simplemente aquel al que otros aspiran, sino que el ritmo de desarrollo de los países industrializados tiene profundos efectos en la posibilidad y la capacidad de todos los pueblos para lograrlo. Es decir, el desarrollo no es simplemente una sucesión de etapas en las que se sitúan unos y otros países, el desarrollo no es tanto una escala sino una trama intrincada de modo que las decisiones de unos afectan invariablemente a los otros. La trama deja ver sus consecuencias: pobreza, degradación, desertización, calentamiento, toxicidad, etc. y desigualdad. El contenido primero de la sostenibilidad es su mejora, su reducción.

Las áreas de la sostenibilidad que la Comisión seleccionó como relevantes fueron la población, el aseguramiento de alimentos, la pérdida de especies y de recursos genéticos, la energía, la industria y los asentamientos urbanos, tomados todos ellos en interrelación. Los análisis de cada una de estas áreas llevan a propuestas multidimensionales específicas, pero en muchas de ellas, de forma transversal y también en forma particular en cuanto a las especies y los recursos genéticos aparece la «diversidad». Ciertamente la diversidad es la cuestión central en relación con las especies silvestres y los recursos genéticos. El enunciado en términos biológicos tiene rango de principio. «La diversidad es necesaria para el normal funcionamiento de los ecosistemas y para la biosfera como un todo» (p. 53). Los fundamentos biológicos del enunciado son complejos, los dos grandes procesos de la vida, la evolución y la adaptación producen diversidad y a la vez son dinamizados por ella que se genera a dos niveles, el de las especies y el de la dotación genética, y ambos son mutuamente indispensables ${ }^{15}$. La evolución futura y las posibilidades de adaptación a los cambios que pueden producirse

15 Wilson, E. O. (1999[1992]). 
dependen de ello. Lo que la pérdida de especies y de recursos genéticos puede suponer lo han expuesto reiteradamente los biólogos ${ }^{16}$.

El informe Brundland afirma además con determinación que la conservación de los recursos naturales es crucial para el desarrollo. El papel que ha de jugar en él tiene una justificación económica considerable (aunque también con aspectos estéticos, éticos y científicos no desdeńables), pues asegurar la supervivencia de las especies significa incrementar la disponibilidad de alimentos, medicinas $\mathrm{y}$ nuevos materiales, y no es menos crucial que proteger a las especies como tales, el proteger igualmente los procesos dentro de los ecosistemas naturales. Particularmente, se hace necesario preservar las singulares reservas de diversidad biológica en bosques tropicales, arrecifes de coral, sabanas, estepas y zonas áridas por el potencial de su variabilidad genética. En la misma medida que las especies es importante preservar las variedades dentro de ellas pues si no se perdería su capacidad para resistir a las adversidades y al cambio climático. El informe Brundland llamaba a elaborar una nueva Convención, la de la diversidad biológica que se hizo en 1992. En ella se recogen todos estos planteamientos del desarrollo sostenible. Establece como objetivo (en art. 1) la conservación de la diversidad biológica, su utilización sostenible y la participación justa y equitativa de los beneficios que se derivan de los recursos genéticos. En ella se define como diversidad biológica la variabilidad dentro de las especies, entre las especies y entre los ecosistemas (art. 2), además de regular la conservación ex situ (art. 9) impone la conservación in situ (art. 8), y para ello entre otras medidas «la preservación, el respeto y el mantenimiento de los conocimientos, las innovaciones y las prácticas de las comunidades indígenas y locales que entrañan estilos tradicionales de vida pertinentes para la conservación y la utilización sostenible de la diversidad biológica,...» (art.8j). No sólo por esto pero fundamentalmente por esto desde entonces se ha ido agudizando la sensibilidad y consolidándose la idea

16 «Esta especie de ensueño amnésico nos hace olvidar fácilmente los servicios que proporcionan los ecosistemas a la humanidad. Enriquecen el suelo y crean el aire que respiramos. Sin ellos, el abastecimiento remanente de la especie humana se haría asqueroso y breve. La matriz que sustenta la vida está hecha de plantas verdes con legiones de microorganismos y animales pequeños y oscuros, en otras palabras, hierbas y bichos. Tales organismos soportan el mundo con eficiencia porque son tan diversos, lo que les permite dividirse el trabajo y pulular por cada metro cuadrado de la superficie de la tierra. Y el mundo marcha como nosotros queremos que marche, porque la humanidad evolucionó dentro de comunidades de seres vivos y nuestras funciones corporales están finamente ajustadas a las condiciones idiosincráticas del medio ambiente ya creado», WILSON (1999), p. 347. 
de que diversidad cultural y diversidad biológica deben concebirse estrechamente asociadas ${ }^{17}$.

Cuando se comparan la visión levi-straussiana de la diversidad (y la colaboración entre culturas) como condición necesaria del Progreso y la visión (en principio vinculada a la biología evolucionista) de la diversidad como condición necesaria del progreso de la vida, aparecen explícitas las concomitancias entre ellas. Presumiblemente la intención de Lévi-Strauss no iba más allá de jugar con un paralelismo que resultaba teóricamente fructífero: en la teoría evolucionista clásica se encontraba un mecanismo explicativo, la diversidad, que de modo semejante permitía iluminar la evolución de las culturas humanas (en un caso la diversidad biológica y en el otro la diversidad cultural). Sin embargo, no es un mero paralelismo lo que se descubre en la crítica ecológica a la teoría del desarrollo. Hay más bien imbricación y reorientación en el ritmo y dirección de los procesos evolutivos. Por un lado, el desarrollo económico y tecnológico que comporta un dominio y control de la naturaleza no es un proceso disociado de la evolución de la vida, sino que la afecta profunda y decisivamente. Y por otro lado, sólo será posible si es sostenible y sólo es sostenible si respeta y mantiene la diversidad biológica y la diversidad cultural, ambas a la vez se entienden coimplicadas, de manera que el respeto y mantenimiento de la diversidad biológica depende en buena medida del respeto y mantenimiento de la diversidad cultural.

\section{Diversidad cultural vs. globalización}

La teoría del desarrollo incorporaba en el diseño clásico de sus fases una modelización de las sociedades humanas ( $\mathrm{y}$ de sus culturas) según los patrones de las sociedades industrializadas y en general de las sociedades occidentales. El trabajo clásico de Rostow $^{18}$ que desglosaba las fases del desarrollo había establecido que «La fase final del proceso tiende a identificarse con el modelo europeo occidental o norteamericano de país moderno». Lo que implicaba a la vez modernización y homogeneización. Y pese a la serie de críticas que a esta secuencia de fases se han ido formulando incluida la del no cumplimiento de las etapas previstas, (el detenimiento prolongado en las fases previas para muchos países, los retrocesos debidos a crisis económicas y en parte también a las catástrofes,

17 Sobre diversidad biológica y diversidad cultural: UNEP (1999); CARLSON (2001); UNESCO\&UNP (2003); PretTy et al. (2008).

18 Rostow, W. (1970 [1957]). 
la persistencia de los conflictos armados y la pauperización de los pueblos, la desigual distribución de la riqueza, etc.), parece haberse ido generalizando la idea de que el proceso era irreversible, no ya el de modelización según patrones occidentales sino el sustrato de interconectividad que conllevaba y se constataba como una evidencia incontestable que de todos modos había sido expansivo y aún más había alcanzado definitivamente a todo el mundo. Es decir, el marco desde el cual tendría que ser contemplado tendría que llamarse ya globalización.

Ese diseño de proceso por fases que delineó la teoría del desarrollo en todo caso quedó — si se permite la expresión — desfasado. E incluso la irreversibilidad ha perdido relevancia como tal, pues más bien queda difuminada, o envuelta en una dinámica que involucra a todo el mundo. La globalización se erigió en marco y horizonte, no sólo subsumiendo al desarrollo sino como trama de complejidad asumiendo ritmos distintos, direcciones distintas, escalas distintas, agencias y agentes de intervención distintos, pero todo a la vez co-implicado. El contexto socio-político es completamente postcolonial, prácticamente todos los procesos de emancipación de los pueblos e independencia de los estados están concluidos y las dinámicas internas en esos nuevos estados están siendo agitadas por los distintos pueblos integrados/segregados en condición de minorías con distintos grados de reconocimiento, mientras que en los viejos estados las corrientes inmigratorias de centenares de miles de personas provenientes de las antiguas colonias o bien de países del tercer mundo han generado otras dinámicas de integración/ segregación por un lado de individuos activos en el mercado de trabajo y del consumo y por otro lado de minorías dispuestas a mantener determinadas prácticas o estilos de vida diferenciados. En direcciones similares otras minorías sociales al tiempo de haber intensificado su presencia y visibilidad social están igualmente involucradas en procesos de reconocimiento de sus derechos políticos y sociales. Y particularmente los movimientos feministas y las mujeres como colectivo no sólo en búsqueda del reconocimiento de los derechos civiles de participación en la vida social, económica y política y en las instituciones sino también de la plena igualdad social. Es teniendo como pantalla de proyección este contexto como toma sentido que las sociedades se redescubran como «multiculturales». El documento «Nuestra Diversidad Creativa» de la Comisión Mundial de Cultura y Desarrollo (1996) remite a este contexto mientras señala como clave a la noción de «cultura». En el Prólogo, Pérez de Cuéllar lo expresa claramente:

«En el mundo entero a medida que los pueblos se mezclaban como nunca antes lo habían hecho, se veían inmersos en marcos de acción más amplios, susceptibles de ofrecerles mayor poder de participación. Sin embargo para la 
mayoría el sistema mundial se tornaba cada vez más desequilibrado, difuso e incoherente, lo cual hizo que muchos recurriesen a la cultura como un medio para oponer resistencia a la entropía del sistema mundial, utilizándola a la vez como baluarte y refugio».

La actuación eficaz en la reorientación del desarrollo que realizó de la Comisión Mundial de Medio Ambiente y Desarrollo le sirvió a esta otra Comisión Mundial de estímulo para apostar por el concepto de cultura. En el que encontró potencia teórica:

- «moldea nuestro pensamiento, nuestra imaginación y nuestro comportamiento",

- «es transmisión de conocimiento y a la vez fuente de cambio, creatividad y libertad»,

- "para los grupos y sociedades es energía, inspiración y empoderamiento»

- «y conocimiento y reconocimiento de la diversidad» (Prólogo, Pérez de Cuéllar).

El informe contiene ya referencias explícitas a la globalización y a la diversidad cultural, pero meramente en esbozo. Con la globalización vuelve a asomar el desarrollo con amenaza de pérdida de la identidad cultural, del sentido de comunidad y del valor personal. Y con la diversidad cultural asoma la tolerancia, pero también el tribalismo como reacción y el relativismo cultural. El documento preconiza sin embargo una ética global. Los derechos humanos, la democracia y el pluralismo vienen al rescate de la diversidad como diversidad creativa. De pasada habría que advertir que el que pudo ser Informe Pérez de Cuéllar no llegó a ser tan influyente como lo fue el Brundland, no dio lugar directamente a una Convención, ni el contenido de ésta (si se la reconoce como la del 2005) no se corresponde más que lejanamente con «Nuestra diversidad creativa».

No debiera pasar desapercibida una doble cara de la diversidad cultural que asoma en el documento y que venía insinuándose desde mucho antes, de forma larvada o claramente manifiesta. (Sigue siendo una fuente de tensión aún no resuelta). Es en el marco de la globalización en el que la muestra el documento "Nuestra diversidad creativa». Habiendo invocado la cultura popular "global» de poderosas presiones y la situación de post-guerra fría, el informe señala «una vuelta al tribalismo» en muchos lugares como reacción «a los efectos alienantes de la tecnología moderna a gran escala y la desigual distribución de los beneficios de la industrialización» que muestra un temor a la "pérdida de identidad, del 
sentido de comunidad y del valor personal». Esta caracterización doble como «tribalismo» y como «identidad y sentido de comunidad» se concreta más adelante en el apartado «Amenazas a la diversidad». Se entendería que este apartado ampliaría lo ya expuesto en relación con la globalización, pero no es así. El apartado dedica su atención en realidad a la diversidad dentro de los estados, "puesto que casi todos son multiétnicos», de entrada advierte que la identificación étnica puede desencadenar un conflicto violento, si se la moviliza y manipula. Puede dar lugar a una política de etnicidad que se sustancia en una lucha por el control del poder del estado y con ella es posible emplear la lengua, la raza o la religión para diferenciar y enfrentar. Los gobiernos así favorecen a grupos identificados y discriminan a otros. Todo este planteamiento, por otra parte bien conocido, tiene como trasfondo ese lado oscuro de la identidad/diversidad que en las relaciones entre los estados, o dentro de ellos, puede conllevar enfrentamientos y conflictos violentos y para las cuales es necesario preconizar tolerancia, respeto, democracia y pluralismo. Sólo dos apartados más adelante el documento se vuelve hacia la defensa de los derechos culturales de las minorías y menciona expresamente a las culturas de los pueblos indígenas, merecedoras «de mucho más respeto» que el que se les otorga. Esta doble —o tal vez múltiple — cara es reveladora de la dificultad y de la complejidad de convertir la diversidad cultural en objetivo de las políticas culturales (y también de las Declaraciones y Convenciones internacionales).

Pese al título, el documento "Nuestra diversidad creativa» ${ }^{19}$ no tenía como contenido primario la diversidad cultural, fue más bien la Declaración Universal de 2001 el documento primero que la UNESCO dedicó expresamente a esta cuestión. El discurso de presentación de la Declaración por parte de Koïchiro Matsuura muestra los objetivos básicos de la adopción por UNESCO de la diversidad cultural como estrategia intelectual con la que dirigir las políticas culturales. La primera referencia es contextual. Acababan de producirse los acontecimientos del 11 de septiembre en Nueva York que se interpretaron bajo el paradigma del choque de civilizaciones. Se estaban cumpliendo las previsiones de Huntington (1993). Para contrarrestarlo y disolver la idea de que resultaría inevitable, la Declaración promueve el diálogo intercultural y como su herramienta conceptual más relevante, la diversidad cultural. Enuncia a continuación lo que debería considerarse segundo principio: la diversidad cultural es patrimonio común de la humanidad. Con dos caracterizaciones, por un lado el refuerzo en paralelo de

${ }_{19}$ Una doble alusión a la fórmula que aparece en la carta constitucional de la UNESCO y al Informe Brundland. 
la diversidad biológica, necesaria para la supervivencia de la especie humana, por otro lado el imperativo ético de salvaguardar con ello la dignidad de las personas. Hay a continuación una mención al lado oscuro de la diversidad, la tentación de sacralizar las diferencias culturales y los fundamentalismos. Y pasa después a enunciar la doble dimensión de la diversidad cultural: como proceso evolutivo y como fuente de innovación y creación. Una doble dimensión que recoge las aspiraciones de muchos estados, unos los que defienden los bienes y servicios culturales por ser portadores de identidad y valores y por tanto no pueden ser tomados como meras mercancías y otros los que esperan fomentar los derechos culturales. Ambas posiciones son complementarias. Hay un leve guiño final al documento «Nuestra diversidad creativa» reafirmando «una nueva ética» que promueve la UNESCO, «frente a la intransigencia fundamentalista». El rango al que aspiraba el director general de la UNESCO era que esta Declaración fuera similar en fuerza a la de los Derechos Humanos.

En el terreno de los conceptos, en la Declaración se recoge una definición de cultura (Considerandos), suscribiendo la de México y en el art. 1 una descripción de la diversidad cultural, que es estrechamente dependiente de la anterior definición de cultura. En la definición de cultura no sólo hay una enumeración de rasgos y ámbitos (las artes y las letras, la manera de vivir juntos, los sistemas de valores, las tradiciones y las creencias) sino también la adscripción de éstos a un sujeto social: las sociedades y grupos sociales, tomados uno a uno. La descripción recoge esta diferenciación de sujetos sociales y muestra la diversidad:

1. Expuesta como una característica de la cultura en el tiempo y en el espacio.

2. Asociándola a la identidad de sociedades y grupos.

Como característica de las formas de la cultura la diversidad es una evidencia. Pero es indispensable marcar que las formas culturales no tienen sentido por sí mismas sino por su atribución a los sujetos sociales, cuya condición básica es la diferencia que se expresa en identidad. La concepción de la cultura como entidad abstracta sin sujeto social es un sesgo común pero claramente inaceptable. El concepto de diversidad cultural conlleva ineludiblemente el reconocimiento de las identidades de las sociedades y grupos sociales (art. 1). Y como se afirma en el art. 2, la diversidad cultural está activa en la trama de la interacción y la convivencia entre personas y grupos «con identidades culturales plurales y dinámicas». Esta es la razón por la que se preconiza el pluralismo cultural, que es «la respuesta política a la diversidad cultural». (El art. 3 es simplemente una secuela 
de la etapa anterior en la que aún se justifica la diversidad cultural como fuente de desarrollo, eso sí, entendido éste tanto económico como humano).

Leída la Declaración en términos de atribución a sujetos sociales de la cultura y de la diversidad cultural se advertirá que en el Art. 4 se mencionan los derechos de las minorías y pueblos autóctonos y en el 5 se reafirma el respeto a la identidad cultural, la participación de la vida cultural que se elija y el ejercicio de las propias prácticas culturales. El enunciado del Art. 6 es singular, en él se mencionan las culturas —en plural, lo que no se había hecho antes en ninguna de las Declaraciones o Convenciones de la UNESCO_ y significativamente se hace así en el contexto de la globalización, particularmente aludida aquí con los medios de comunicación, de expresión y difusión. De esta manera se les otorga a las culturas el carácter de entidades, como si fueran sujetos sociales. Donde más claramente se muestra en la Declaración la atribución de la diversidad cultural a los sujetos sociales es en el enunciado de objetivos del Plan de Acción ${ }^{20}$. Se establecen 20. Salvo los dos primeros autorreferenciales, el resto se refieren a distintos ámbitos y con ellos a distintos sujetos:

a. Conocimientos y prácticas, derechos culturales, lenguas, transmisión oral del saber, patrimonio cultural (e inmaterial), conocimientos tradicionales (puntos n. $\left.{ }^{\circ} 3,4,5,6,14\right)$. El sujeto social de todos ellos son "pueblos» (también particularizados en algunos casos como pueblos autóctonos o como minorías).

b. Derechos de autor, movilidad de artistas y científicos, industrias culturales $\left(n .^{\circ} 15,16,17\right)$. Los cuales por numerosos documentos anteriores se sabe que son atribuidos a «individuos».

c. Educación, productos culturales endógenos, servicios públicos de radiodifusión y televisión, patrimonio cultural (e inmaterial), bienes y servicios culturales, políticas culturales $\left(n .^{\circ} 6,7,8,9,13\right)$. Los cuales claramente remiten a «estados».

d. Tecnologías de la información, espacios cibernéticos, redes mundiales, medios de comunicación, mercados mundiales (n. $\left.{ }^{\circ} 10,11,12\right)$. Procesos destacablemente sin sujeto social y que se encuadran en los procesos de la «globalización».

El desglose de los ámbitos de la diversidad cultural es pertinente no sólo por tener constancia de ellos sino fundamentalmente porque revela los distin-

20 Se diría que esta serie de objetivos fue un manifiesto intento de especificar los contenidos de una futura Convención de Diversidad Cultural, a la que se alude en el primero de ellos. 
tos sujetos sociales implicados. Cuando se proyectan las ideas contenidas en el art. 1, la implicación de los sujetos sociales toma configuración en tanto que identidad. Pero este concepto propiamente es aplicable sólo a las sociedades y grupos sociales y a los individuos, pues los estados y sobre todo los procesos de la globalización tienden más bien a imponer la homogeneización. La imagen sugerida es que el reconocimiento de la diversidad cultural es lo que se requiere para que la identidad cultural de sociedades, grupos sociales e individuos no se vea oscurecida o menoscabada por las políticas culturales de los estados o por los procesos de la globalización (en los que domina la tecnología y los intereses mercantilistas). En este en principio simple esquema cabe hacer dos diferenciaciones de distinto signo. Por un lado la identidad cultural de las sociedades (y grupos sociales) no coincide en los mismos ámbitos con la de los individuos en tanto que tales. La individualización es uno de los procesos más característicos de la modernización y por otra parte es el cultivo de las ciencias, las artes y las letras el que está dirigido a destacar individualidades encomiadas por la excelencia de sus capacidades y habilidades ${ }^{21}$. También se hace necesario distinguir entre los estados pues muchos de ellos ocupan claramente posiciones de dependencia o de subordinación agudizadas especialmente en la dinámica de los procesos de la globalización. (A su modo demandan un trato similar al que se reclama para las sociedades tradicionales, las minorías, los grupos autóctonos).

En la Declaración no se especifica pero se podría dar por supuesto que las amenazas implícitas a la diversidad cultural, diferenciada según los sujetos sociales implicados y en cuanto a su identidad cultural afectados, son bien distintas. Los pueblos ven desvalorizados, postergados, sus conocimientos y prácticas, debilitadas, si no moribundas sus lenguas, quebrada la transmisión oral del saber y minusvalorado o destruido su patrimonio cultural (e inmaterial). Los individuos por su parte ven menospreciados sus derechos de autor, reducida o imposibilitada su movilidad, debilitadas o desaparecidas sus industrias por la masiva difusión de productos standard, desprovistos de originalidad y con gustos impuestos. Los estados menos desarrollados se ven incapaces de detener la invasión de bienes y servicios culturales provenientes de los estados poderosos, sin capacidad de reacción para destinar recursos e invertir en tecnología para contrarrestarla. La fuente primordial de las amenazas se sitúa más que en un lugar o lugares concretos en un horizonte englobante, la mundialización.

${ }^{21}$ En general la obra de Max Weber desarrolla la relación entre individualismo y modernidad. También Dumont, L. (1987) Ensayos sobre el individualismo. Madrid: Alianza; Elias, N. (1987) El proceso de civilización. México: F. C. E.; BÉJAR, Helena (1990) El ámbito intimo. Madrid: Alianza. 
Es en esta línea en la que las reflexiones de Arjun Appadurai han venido a abundar. Los desafíos que enfrenta la diversidad cultural en los tiempos recientes son identificados por este autor ${ }^{22}$. En primer lugar, la globalización, que ha generado nuevas formas de desigualdad, generada ya de manera reconocida por conflictos culturales. En segundo lugar, los estados hoy con dificultades para canalizar los flujos de ideas e imágenes que vienen del exterior y que les afectan. $\mathrm{Y}$ en tercer lugar la desigual alfabetización digital y convencional que favorece el monopolio elitista y genera excluidos culturales y a la vez mayor marginación. Es García Canclini quien ha añadido entre las poblaciones más vulnerables a los desconectados ${ }^{23}$. Appadurai propugna un replanteamiento del desarrollo humano como desarrollo sostenible, en el que se incentiva la participación de todos, de las poblaciones más vulnerables, de la gente común, de las comunidades locales, las mujeres y los nińos, para la cual es un requisito indispensable la cultura, como recurso colectivo de diversidad de formas y de tolerancia, convivencia y diálogo, es decir, el requisito lo son las culturas en diversidad.

El lado oscuro de las diferencias culturales en la Declaración está debidamente tratado con la reafirmación de la primacía del respeto hacia los derechos humanos. «Nadie puede invocar la diversidad cultural para vulnerar los derechos humanos», está escrito en el art. 4. Appadurai propone otros modos previos de tratamiento. Está implícito en la Declaración que el término «diversidad cultural» se perciba cargado fundamentalmente de significados positivos. "La diversidad cultural va más allá de las diferencias culturales», escribe haciéndolo explícito, desmarcándose así del término de las «diferencias culturales» con las que se hace alusión a ese lado oscuro. Y aún más subrayando algunos otros aspectos esenciales que se proponen para ser incorporados al concepto de «diversidad cultural».

a. es mucho más que una lista abierta de diferencias y variaciones;

b. un valor que más que extremar las diferencias las contempla mutua y recíprocamente relacionadas;

c. un valor que expresa otros valores fundamentales como la creatividad, la dignidad, el sentido de comunidad;

d. conlleva el compromiso moral de los actores y sujetos que pertenecen a las comunidades culturales específicas;

e. está estrechamente interrelacionada con la diversidad biológica.

22 Appadurai, A. (2002) «Diversidad sostenible. La indivisibilidad de la cultura y el desarrollo». En Declaración Universal sobre la Diversidad Cultural. París: UNESCO, pp. 9-16.

${ }^{23}$ García Canclini, N. (2009). 
En suma, «diversidad cultural» no es tanto una propiedad o una característica de los objetos o productos culturales sino una noción fuerza que conlleva nuclearmente la implicación de los sujetos sociales y una estrecha interrelación con la diversidad biológica y que puede proporcionar desarrollo sostenible y afrontar los desafíos de la globalización. La Convención demandada en esta Declaración Universal llegó en 2005. En medio, la Convención del Patrimonio Cultural Inmaterial de 2003 estaba ya teñida de diversidad cultural. El Patrimonio Cultural Inmaterial correspondía de forma paradigmática al núcleo de la noción de diversidad cultural que Appadurai había identificado y que se recogía en los artículos primeros de la Declaración. El contenido al que se alude en el título de la Convención de 2005 no tanto, pues su ámbito se redujo a los productos culturales y las expresiones artísticas ${ }^{24}$, en primera formulación luego abreviada como «expresiones culturales». Esta reducción ha de ser subrayada en primer lugar y, en contraste con la Declaración, parece desligarse de la implicación con los sujetos sociales incluida en la noción de diversidad cultural para pronunciarse más bien a favor de la vinculación de esta noción con los productos culturales como un atributo de éstos. Significativamente el título abandona el término de "diversidad cultural» y lo sustituye por «diversidad de las expresiones culturales». Conocida la historia de la gestación de la Convención y las estrategias en función de los distintos intereses de las principales agencias y agentes negociadores habría que reconocer que la reducción de ámbito y la sustitución del término se produjo en el marco y ante el horizonte de la globalización. Se diría que el término «diversidad cultural» se desdobló, así cobró relevancia y sentido autónomo la "diversidad», mientras que la «cultura» quedó subordinada y de hecho reelaborada como cualidad, o si se quiere, como valor relativo a los productos, a las expresiones. No ya como concepto holístico vinculado a los sujetos sociales. Enseguida se dibuja la disculpa de la dificultad de convertirle en objeto para una normatividad precisa dada su gran complejidad, pero de todos modos queda la coartada de acogerse al concepto humanístico de cultura y de hecho las expresiones mencionadas en las primeras formulaciones fueron las «artísticas».

En todo caso en el texto de la Convención aparece un doble discurso, ya vieja pauta de otros anteriores documentos (antes señalados), esta vez distribuidos entre el Preámbulo y el articulado. En el primero han quedado los enunciados sobre diversidad cultural que emplean el concepto antropológico de cultura, en el articulado los que emplean el concepto humanístico que se reconoce en las acti-

${ }^{24}$ Primera formulación en el grupo de expertos independientes. Ver Barreiro (2011), p. 176. 
vidades, bienes y servicios culturales. En el Preámbulo el rasgo distintivo del uso del concepto antropológico de cultura es la vinculación a sujetos sociales como la humanidad, los pueblos, las comunidades, los pueblos autóctonos, las minorías, etc. (párrafos 1, 2, 3, 4, 7, 13, 15...). Otro rasgo distintivo es el uso en plural de "culturas», si bien en algunos casos el sujeto social es indefinido, pudieran ser bien los pueblos o bien los estados $(11,15,19,20)$. En otros párrafos hay una cuidada ambigüedad de modo que pueda entenderse que se refiere tanto a individuos sujetos de derechos como a grupos y sociedades (párrafos 12, 14). Sin embargo en el articulado, una vez expuestos los principios y las definiciones, en todo el texto relativo a los derechos de las partes y a las medidas de protección y promoción ya no hay ninguna mención a los pueblos, las minorías o las sociedades, ni tampoco a las culturas. En el Apartado IV los sujetos mencionados son los estados. Y al desglosar las medidas de protección y promoción los sujetos a los que se aluden son entidades públicas y privadas, artistas y otros profesionales de la cultura. Con una sola excepción, en el art. 7 punto 1 se mencionan a «las mujeres y distintos grupos sociales, comprendidas las personas pertenecientes a minorías y grupos autóctonos».

La Convención pretende ser doctrinal y forjar definiciones incuestionables. La intención doctrinal se plasma en el artículo 2, que contiene ocho principios rectores. Cuando se compara su exposición con los enunciados que aparecen en la Declaración Universal de 2001, su antecedente inmediato, se observa un significativo cambio en la secuencia y la lógica de orden que enlaza la serie:

\begin{tabular}{|l|l|}
\hline DECLARACIÓN 2001 (Artículos 1 al 6) & CONVENCIÓN 2005 (Artículo 2) \\
\hline $\begin{array}{l}\text { La diversidad, patrimonio común de la } \\
\text { humanidad }\end{array}$ & P. de respeto de los derechos humanos \\
\hline $\begin{array}{l}\text { La diversidad se concreta en pluralismo } \\
\text { cultural }\end{array}$ & P. de soberanía de los estados \\
\hline La diversidad es factor de desarrollo & P. de igual dignidad de las culturas \\
\hline P. de respeto de los derechos humanos & P. de cooperación internacional \\
\hline P. de respeto de los derechos culturales & $\begin{array}{l}\text { P. de complementariedad de lo econó- } \\
\text { mico y lo cultural en el desarrollo }\end{array}$ \\
\hline P. de libre acceso & P. de desarrollo sostenible \\
\hline & P. de acceso equitativo \\
\hline & P. de apertura y equilibrio \\
\hline
\end{tabular}


Se advierte de entrada en la Declaración la especificidad de los principios en relación con la diversidad cultural frente al conjunto de principios generales que presenta la Convención, dentro del cual sitúa los específicos de la diversidad cultural. En la Declaración los principios se enuncian aludiendo a los distintos aspectos relevantes de la diversidad que se complementan entre sí. En la Convención se entendería que la serie se despliega con cierta redundancia justificada por cierto requerimiento de consonancia con otras declaraciones y convenciones y al menos cinco principios trasladan doctrina ya expuesta en otros documentos. El esfuerzo en la elaboración doctrinal de la Declaración no se continúa en la Convención sino que más bien ésta parece responder a una percibida necesidad de articular su contenido con otras disposiciones. Así aparecen los principios específicos de la Diversidad cultural arropados por otros principios comunes que por un lado contribuyen a darle dimensión transversal y por otro lado parecen responder a la necesidad de subordinarla y limitarla. Así se entendería la primacía explícita del principio de respeto de los derechos humanos («Sólo se podrá proteger y promover la diversidad cultural si se garantizan los derechos humanos y libertades fundamentales...») y del principio de soberanía («Los estados tienen el derecho soberano de adoptar medidas para proteger y promover la diversidad de las expresiones culturales en sus territorios»). La presencia en ambos documentos del P. de libre acceso (o de acceso equitativo) es una coincidencia nada irrelevante. Responde al reconocimiento de la realidad de las constricciones de diversidad cultural en los procesos de globalización, la extensión mundial de los medios de comunicación, su proliferación, la circulación incesante y sin límites de información, la intensidad de su presencia en la vida social y los avances continuos en los desarrollos tecnológicos de la difusión. El libre acceso (matizado en la Convención como "equitativo») se convierte en la garantía de la diversidad cultural. El contexto literal indica que en la Declaración el sujeto para el que se postula son las culturas («Hay que procurar que todas las culturas puedan expresarse y darse a conocer»), en la Convención el sujeto es difuso y el enunciado indica claramente que el acceso que se demanda es a las expresiones culturales. Al mencionar como un ańadido a las culturas preconizando su «acceso a los medios de expresión» es posible encontrar lo "cultural» a la vez como sujeto y como término de acceso y las «expresiones» como objeto y como medio. Desconcertante enunciado frente a la clara identificación en la Declaración de las garantías de la diversidad cultural en el marco de la globalización: la libertad de expresión, el pluralismo de los medios de comunicación, el multilingüismo, y la igualdad de acceso al arte y al saber científico-tecnológico. 
Es obvio que de la Declaración a la Convención se ha producido la ausencia de dos enunciados doctrinales de la Diversidad cultural de gran calado. En el caso del pluralismo cultural («El pluralismo cultural es la respuesta política al hecho de la diversidad cultural» (art. 2), la ausencia es completa. Y en el del respeto de los derechos culturales (art. 4) se pasa de una formulación enfática («Toda persona debe así poder expresarse, crear y difundir sus obras en la lengua que desee y en particular en lengua materna, toda persona... tiene derecho a una educación..., toda persona ... que respete plenamente su identidad cultural, toda persona debe poder... ejercer sus propias prácticas culturales...») a que en la Convención éstos de una manera específica no sean mencionados y si acaso estén meramente aludidos en la glosa del principio de respeto de los derechos humanos de forma tan suave como «... y la posibilidad de que las personas escojan sus expresiones culturales».

La renuncia al pluralismo cultural se entiende en la medida en que el conjunto de los principios de la Convención forman un corpus doctrinal para la gestión de los productos culturales en la globalización. La reafirmación de los individuos como sujetos sociales y de sus derechos humanos y libertades fundamentales y la reafirmación de los estados y de su soberanía constituyen el supuesto en cuanto establecimiento de los sujetos implicados y en cuanto a corpus doctrinal básico de los demás principios: el de la cooperación internacional, el de la complementariedad de lo económico y lo cultural en el desarrollo y el principio de apertura y equilibrio. El de solidaridad y cooperación internacional recoge los principios de la Declaración de 1966, remite inequívocamente a los estados, con una mención especial a los "países en desarrollo", pero también, y puesto que lo es de solidaridad, a los desarrollados en su desigual posición en los procesos de la globalización. El de complementariedad de lo económico y lo cultural en el desarrollo recoge la doctrina generada en el Declaración de México de 1982, y menciona como sujetos a los individuos y a los pueblos (pero la mención a éstos asume infundadamente que su cultura acepta esa complementariedad y que el sentido de ella es el que se supone compatible con el desarrollo). Y el principio de apertura y equilibrio está explícitamente referido a los estados y les urge a la vez a respaldar la diversidad de las expresiones culturales y a "promover la apertura a las demás culturas del mundo». Comprendido en el marco de la globalización y puesto que el objeto son las expresiones culturales este principio pretende trasladar a un nivel abstracto una hábil política de doble filo, por un lado favoreciendo la excepción cultural y por el otro permitiendo el libre comercio. Si el objeto fuera la diversidad cultural el principio resultaría simplemente contradictorio. Tendría al menos que haber matizado el significado de equilibrio y en este sentido recogería las viejas sugerencias de Lévi-Strauss cuando sugería 
que las sociedades necesitan a la vez cerrarse en sí mismas y abrirse a cooperar con las otras, sin romper el equilibrio, pues si se abren corren el peligro de perder identidad y si se cierran no progresarán ${ }^{25}$.

Dentro de la serie de principios está el de la igual dignidad de las culturas y el respeto de ellas, glosado como un supuesto de la diversidad de las expresiones culturales, pero resulta una cobertura demasiado elevada y que sobrepasa en exceso aquello a lo que se aplica. Si la Convención hubiera sido de la Diversidad Cultural ese principio probablemente hubiera sido desarrollado y de acuerdo con posicionamientos adoptados en otros documentos anteriores podrían haberse expuesto de forma conjunta al menos otros Principios, a saber:

1. Toda cultura tiene una dignidad y un valor que deben ser respetados y protegidos.

2. Todo pueblo tiene el derecho y el deber de desarrollar su cultura.

3. En su fecunda variedad, en su diversidad y por la influencia recíproca que ejercen unas sobre otras, todas las culturas forman parte del patrimonio común de la humanidad. (Los tres estaban ya en la Declaración de la Cooperación Cultural Internacional de 1966, el segundo de ellos no volvió a aparecer).

4. La diversidad cultural es potencialmente dinámica y es fuente de innovación y creatividad (Nuestra diversidad creativa, 1992).

5. La diversidad cultural amplía las posibilidades de elección que se ofrecen a todos. (En la Declaración Universal de 2001 se asocia este enunciado con el énfasis en ser factor de desarrollo no sólo económico sino también humano).

6. La diversidad cultural se concreta políticamente en pluralismo cultural.

7. La diversidad cultural da fundamento a los derechos culturales. (Estos dos en la Declaración Universal de 2001).

8. La diversidad cultural está estrechamente involucrada en el mantenimiento de la diversidad biológica y posibilita el desarrollo sostenible. (En la Convención de la Biodiversidad 1992 y Cumbre de Johannesburgo 2002).

9. La diversidad cultural debería estar presente en los medios de expresión y difusión respetando la voluntad de las sociedades y grupos sociales y sin deformaciones ni prejuicios. (En la Declaración de 2001 con matices).

Y por otro lado el programa que podría haber abordado una Convención de la Diversidad Cultural está bien aclarado: el pluralismo cultural, los derechos

25 LÉvi-Strauss en «Raza e Historia». 
culturales, el patrimonio cultural, la creatividad, y el intercambio de los productos culturales, la promoción de industrias culturales, la distribución online,...

\section{La diversidad cultural ya no es lo que era. Conclusiones}

Es evidente que en el siglo XXI la diversidad cultural ya no es lo que era. En el 2010 el Informe sobre la Cultura Mundial «Diversidad cultural, conflicto y pluralismo» llevaba ya esta advertencia: «En la actualidad la globalización, las telecomunicaciones y la informática han cambiado la forma en que la gente identifica y percibe la diversidad cultural. En particular la metáfora gastada del «mosaico de culturas» o del "mosaico cultural global» ya no describe las diferentes preferencias culturales de los pueblos. Las culturas ya no son contenedores fijos, delimitados y cristalizados como se creía que eran antes. Más bien son creaciones que traspasan los límites y son intercambiadas a través del mundo vía los medios y el internet. La cultura debe ser vista como un proceso mas que como un producto acabado» (Prefacio). No sólo se han producido notables cambios en el concepto de cultura con la adopción de la perspectiva antropológica, también se han producido en la consideración de las culturas como procesos y no sólo como productos ${ }^{26}$. Si bien el interés fundamental prestado a la libre circulación de bienes y servicios insiste en los productos, lo que conlleva un sesgo en la consideración de la diversidad cultural que incluso evita la percepción de que los procesos del intercambio también tendrían que ser contemplados como ámbito de la diversidad cultural, asumiendo, sin embargo, que siendo dominios tecnológicos están de hecho bajo la hegemonía de las sociedades desarrolladas. La globalización además parece haberlos consagrado como indispensables. Las implicaciones de la consideración de las culturas como procesos incluyen especialmente al patrimonio cultural y natural, tangible e intangible particularmente proclive a ser objetualizado. Appadurai ${ }^{27}$ había propuesto de forma audaz modificar la perspectiva de aproximación destacando la doble articulación del patrimonio cultural con la creatividad, y del patrimonio inmaterial con el desarrollo sostenible. Lo que significa situar el patrimonio no en un muestrario a contemplar sino en los pueblos y las sociedades mirando en el pasado para ir creando el futuro. El patrimonio inmaterial además, entramado con el desarrollo, deshace esa dicotomía que tenía la teoría clásica entre los valores economicistas

${ }^{26}$ Velasco, H. M.(2006) «La cultura noción moderna». Patrimonio cultural y derecho 10: 11-34.

27 Appadurai (2002). 
y los valores espirituales o humanos y que se recoge en uno de los principios de la Convención de 2005. (El documento sí se sitúa en la perspectiva del proceso en particular en relación a los productos artísticos atendiendo a cinco fases: creación-producción-difusión-distribución-disfrute).

La diversidad cultural no es lo que era tampoco en cuanto a los marcos de contraste. Aunque muy pocas veces se ha tratado de forma explícita, la diversidad cultural referida por contexto podría identificarse como aquella que se distingue entre los estados. Especialmente en documentos importantes como la Declaración de los principios de la Cooperación Cultural Internacional, en la que por otra parte se enuncian los principios primarios de la diversidad cultural, que sin embargo en ese contexto debe entenderse diversidad «inter-naciones». Los documentos relacionados con el libre intercambio de bienes y servicios culturales participan de este marco. Luego, los documentos que mencionan explícitamente a las minorías y a los pueblos autóctonos (como la Declaración de 2001, y antes el «Nuestra diversidad creativa», pero también la Convención de la Biodiversidad 1992) dirigen la atención hacia la diversidad cultural intra-nacional. Pero el principio de soberanía recordado en la Convención de 2005 a continuación de la Declaración de los Derechos Humanos mitiga la relevancia del marco intranacional y vuelve a enmarcar la diversidad entre los estados. La radicalidad de los principios de la Declaración de 2001 y la focalización de la diversidad cultural en los sujetos sociales y no en los productos culturales tendría que haberse desligado del marco estatal como a veces parece que pretenden hacerlo aquellos textos que la atribuyen a «las culturas». Es que enunciada la cultura en plural lo es de diversidad.

Como ha señalado Geertz ${ }^{28}$, tampoco las culturas en su diversidad ya no son las mismas. Los procesos de la globalización han dado una enorme fluidez a las culturas ya no contenidas en enclaves territoriales ni en las mentes de individuos con identidades esencialistas, sino expandidas por todo el mundo por poblaciones resituadas tanto en el centro de las ciudades como en lo recóndito de las selvas, tanto en espacios físicos como en redes virtuales. $\mathrm{Y}$ sin embargo proliferan los acontecimientos de exhibición de las identidades culturales, las reclamaciones de discriminación positiva, los argumentos culturales ante los tribunales de justicia y las demandas de los pueblos autóctonos contra los estados y las compañías internacionales, etc. Los ámbitos de convivencia en los cuales se hace visible la diversidad cultural se encuentran por todas partes. No resul-

28 GeErtz (1996). 
ta menos indispensable el diálogo intercultural entre los estados que entre las poblaciones que conviven en ellos. Tampoco son menos dramáticos los conflictos interculturales que los conflictos de intereses económicos. Y por otro lado no es menor la creatividad por hibridación que la estimulada por las academias institucionales. Las sociedades mayores no son ya homogéneas, ni tampoco muchas comunidades locales, y los procesos de identidad cultural tienen tanto episodios de pureza como de mixtificación. Asumiendo estos planteamientos cabe señalar finalmente algunos de los puntos más destacables en los que el Informe Mundial debería haber profundizado:

- En el seno de UNESCO $^{29}$ está reconocido que la Convención de 2005 no concierne a todos los aspectos de la diversidad cultural si no a los artículos 8 al 11 de la Declaración. Apenas es ya reconocible en ella la vieja cuestión de la excepción cultural pero presumiblemente está inspirada en la necesidad de superarla ${ }^{30}$. Y responde en buena medida a instancias provenientes de los países que defendieron la excepción cultural ante las tendencias advertidas del mercado de las comunicaciones ${ }^{31}$. También en la necesidad de reformular los principios que animaron la Declaración de la Cooperación cultural internacional en términos de política cultural actual. Las expresiones culturales parecen haber sido el nivel mínimo o el ámbito aceptablemente acotable de la diversidad cultural en el que cabría esperar un acuerdo suficientemente general por parte de los Estados. Mientras tanto en otras secciones de Naciones Unidas se han estado debatiendo posicionamientos de diversidad cultural comprometidos como, por ejemplo, en cuestiones sobre las "prácticas

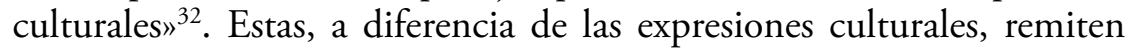
centralmente a los sujetos sociales y a "las culturas». Las expresiones culturales no obstante pueden haber sido redimensionadas como elementos del diálogo intercultural y como sustratos de creatividad. De modo que la presencia de los principios doctrinales de la diversidad cultural en la Convención se convierten en recursos retóricos con efectos performativos en las políticas culturales. En todo caso la efectividad de la Convención ha sido seguida con celo institucional como muestran los Informes regulares. Es sintomático que el Informe mundial de 2010 explícitamente adopte la diversidad cultural (y no la diversidad de las

29 Stenou (2007), p. 134.

30 Prieto (2005).

31 Barreiro (2011).

32 Los campos concretos objeto de atención por el Consejo de Derechos Humanos pueden verse en los informes de la relatora especial Farida Shaheed entre 2012 y 2013. 
expresiones culturales) como foco de atención y así se muestra en el título ligándola con el diálogo intercultural. El Informe contiene una exposición detenida y un desglose de contenidos. Lo que dice y no dice el Informe es lo que se relaciona a continuación a modo de conclusión. Hay razón para el que Informe insista en aspectos que tendrían que ser obvios: como asumir las culturas no como entidades fijas en el tiempo sino cambiantes y en continuo proceso de transformación. Lo que las hace específicas no son las formas de sus creencias, valores o costumbres, sino los modos como se modifican en el tiempo. Tendría que utilizarse con sus matices la terminología "cultura», "civilización», "pueblo", por las connotaciones que suelen portar tales palabras.

Sería obligado reconocer que la diversidad se desarrolla en niveles, no sólo entre naciones o en el interior de ellas sino también entre grupos y entre individuos. Y no está demás insistir en que el efecto primario de esta toma de conciencia de la diversidad cultural es la liberación de estereotipos y prejuicios, la posibilidad del diálogo y el descubrimiento del «carácter humano común». Es el gran recurso del que dispone la cooperación que favorece el desarrollo y la paz.

- El Informe declara de entrada que la diversidad cultural "es un hecho» (p. 4), pero en realidad ya no es simplemente un hecho, convertido en dato al modo como lo hacía la vieja Etnología, archivado y expuesto en una vitrina museológica; más bien lo que se afirma es que su percepción, la toma de conciencia de ella, se ha convertido en un lugar común (p. 4), que se ha hecho más notoria merced a y en el seno de los procesos de mundialización de los intercambios, los flujos multidireccionales de poblaciones, de información y de capitales (p. 14-15), etc. Más que un "hecho» en sí es un hecho percibido con tal grado de imponente evidencia que resulta ineludible. El Informe debería decir que no se puede obviar, que tiene implicaciones sociales y políticas relevantes, tales como negar la pretendida homogeneidad de las sociedades nacionales o la idealizada ciudadanía mundial. Y además, lo que la mundialización añade es que esa toma de conciencia, ese «hecho», se produce porque es una caracterización de un conjunto.

- Por supuesto, la diversidad cultural no se queda en el plano de la contemplación, sino que es una cuestión social, una cuestión de experiencia, y de convivencia; las sociedades — incluida la sociedad-mundo - han devenido en ser pluriculturales y las interacciones sociales en interculturales; la notoriedad ya no es cuestión de apreciación de exotismo y extrañamiento sino confrontación de estilos de vida diferentes en los mismos o próximos espacios de relación por lo que se toman como alternativas coimplicadas.

- La diversidad no es tanto cuestión de contraste entre los objetos, las expresiones, los comportamientos o los textos de las creencias,... sino 
que con ellos se posicionan las personas, los grupos, las sociedades; de modo que la diversidad cultural involucra a los sujetos sociales, en su condición individual y en su condición de pertenencia a los grupos y sociedades, es decir, la diversidad cultural en mundialización es el campo común, compartido, donde se dramatiza el juego de las identidades culturales (pp. 20-23). El Informe menciona en particular a: las comunidades locales, los pueblos indígenas, los grupos desfavorecidos o vulnerables y las personas excluidas por su origen étnico, filiación social, edad o sexo,... Pero en realidad esta mención no oculta que respecto a las «sociedades" generales y las «estructuras políticas oficiales» estos sujetos sociales suponen «nuevas» formas de diversidad. Cabe resaltar esta supuesta novedad de la diversidad caracterizada por el Informe, que no puede serlo estrictamente cuando estas minorías vienen reclamando visibilidad hace tiempo, más bien la novedad está en la potencia de desafío que han alcanzado y en lo que supone en el marco de la mundialización. Sigue siendo innegable que la configuración de diversidad no la proporciona la variedad — por amplia que sea- de las poblaciones, sociedades, pueblos, comunidades, minorías,... del mundo, sino más bien determinadas poblaciones, sociedades, comunidades y minorías en contraste. $^{33}$

- Y porque está amenazada (pp. 17-19); el Informe ya advierte que su mayor notoriedad por sí sola no conlleva necesariamente su preservación. La enumeración de amenazas puede ser muy larga en el caso de las expresiones culturales, lista que en las reivindicaciones de la excepción cultural comenzaba por el cine y los productos audiovisuales y que en los listados de Patrimonio Cultural Inmaterial se puede apreciar lo variado que pueden llegar a ser, lenguas, artesanías, músicas, conocimientos tradicionales, rituales curativos, procedimientos de adivinación, técnicas y modelos de construcción arquitectónica, etc., etc., pero ya advirtió Lévi-Strauss que lo decisivo no es la pérdida de algunas de estas valiosas expresiones o prácticas culturales, sino de la diversidad misma. Y bien parece que en esto el Informe intenta corregir el planteamiento de la Convención de 2005.

- El Informe desglosa los siguientes contenidos del concepto de cultura, respecto a los cuales se constata la experiencia de la diversidad: los estilos de vida, las representaciones sociales, los sistemas de valores, los códigos de conducta, las relaciones sociales (entre generaciones, entre hombres y

33 Sería necesario establecer algunas importantes distinciones entre: grupos étnicos que han alcanzado en los estados reconocimiento y agencia (maoríes, samis, aborígenes australianos,...), minorías nacionales con reconocida capacidad de autogobierno e inmigrantes en los estados del primer mundo. 
mujeres, etc.), las formas y los registros lingüísticos en una determinada lengua, los procesos cognitivos, las expresiones artísticas, las nociones de espacio público y privado (con especial referencia a la planificación urbana y al entorno de vida), las formas de aprendizaje y expresión, los modos de comunicación, los sistemas de pensamiento, ...Estos son ámbitos abstractos. A menudo las caracterizaciones de la diversidad cultural en las sociedades multiculturales son concretas, se han servido de determinadas prácticas o expresiones, por ejemplo, cocina, vestido, música $^{34}$, que Kymlicka ${ }^{35}$ ha criticado como propias de los discursos post-multiculturales cuyo efecto es la trivialización de la diversidad entregando elementos absorbidos por el mercado a modo de souvenirs. Las expresiones culturales tomadas aisladamente por el mercado sufren de un sesgo semejante. Parece en ocasiones que fueran reductos de resistencia (y diversidad) frente a masivas invasiones de productos standard, pero no bastan para sostener sólo con ellas identidades incólumes. El Informe debería añadir que más bien la generalización de la diversidad de las expresiones culturales en la mundialización parece estar contribuyendo a la hibridación de las culturas ${ }^{36}$.

- Ciertamente la diversidad cultural suele formularse en términos -que el Informe llama «sucedáneos»—, lingüísticos, de afiliación religiosa, o de morfología corporal, color de piel, etc. Algunos de ellos se erigen en signos paradigmáticos con capacidad para focalizar la identidad en torno a él. El Informe propugna reducir su transcendencia e instalarse en una noción omnicomprensiva de cultura para evitar reduccionismos, pues de esa manera se propician segregaciones y disociaciones irreconciliables. El Informe debería añadir que la diversidad cultural se empequeñece así. Pues las culturas en interrelación no necesariamente divergen del todo y en todos sus diferentes ámbitos.

\section{Documentos citados}

Declaración sobre la raza. París, julio 1950.

Declaración sobre la naturaleza de la raza y diferencias sociales. París, junio 1951.

Propuesta sobre los aspectos biológicos de la cuestión racial. Moscú, agosto 1964.

34 Alibhai-Brown (2000). Hablando de samosas, tambores de chapa y saris en las Islas Británicas.

35 KyMlicka (1995).

36 García Canclini, N. (2010). 
Declaración sobre la raza y los prejuicios raciales. París, septiembre 1967.

Declaración sobre la raza y los prejuicios raciales. París, noviembre 1978.

Acuerdo para la importación de objetos de carácter educativo, científico o cultural aprobado por la Conferencia General de la UNESCO en Florencia en 1950. Protocolo del Acuerdo para la importación de objetos de carácter educativo, científico o cultural aprobado por la Conferencia General de la UNESCO en Nairobi en 1976.

Convención Universal sobre Derecho de Autor. Ginebra, 1952.

Declaración de los Principios de la Cooperación Cultural Internacional. París, noviembre 1966.

Convención sobre las medidas que deben adoptarse para prohibir e impedir la Importación, la Exportación y la Transferencia de Propiedad Ilícitas de Bienes Culturales. París, noviembre 1970.

La Convención sobre la protección del Patrimonio Mundial Cultural y Natural. París, noviembre 1972.

Recomendación relativa a la condición del artista. Belgrado, octubre 1980.

Recomendación sobre la salvaguardia de la cultura tradicional y el folklore. París, noviembre 1989.

Conferencias intergubernamentales sobre políticas culturales (Venecia 1970, Helsinki 1972, Yogyakarta 1973, Accra 1975, Bogotá 1978 y México).

Declaración de México sobre Políticas Culturales. México 1982.

Informe del Programa de Naciones Unidas para el Desarrollo. (A partir de 1990 se hace un informe anual, e informes nacionales y regionales). (El de 1990 tiene como contenido: Concepto y Medición del Desarrollo Humano).

Nuestro común futuro. Informe de la Comisión Mundial de Medio Ambiente y Desarrollo. (Informe Brundland). Naciones Unidas 1987 (1982).

Declaración de Río sobre Medio Ambiente y Desarrollo. Conferencia de Naciones Unidas sobre Medio Ambiente y Desarrollo. Río 1992.

Convención sobre la Diversidad Biológica. 1992.

«Nuestra Diversidad Creativa». Informe de la Comisión Mundial de Cultura y Desarrollo (Javier Pérez de Cuéllar). París 1996.

Conferencia intergubernamental sobre políticas culturales para el desarrollo. Estocolmo, 1998.

Convención sobre la protección del patrimonio Cultural Subacuático. París, noviembre 2001.

Declaración Universal sobre la Diversidad Cultural. París, noviembre 2001.

Convención para la salvaguardia del Patrimonio Cultural Inmaterial. París, octubre 2003. 
Convención sobre la protección y promoción de la Diversidad de las Expresiones Culturales. París, noviembre 2005.

Informe Mundial: Invertir en la diversidad cultural y el diálogo intercultural. París: UNESCO, 2010.

\section{Bibliografía}

Alibhai-Brown, Y. (2000). After Multiculturalism. London: Foreign Policy Centre.

Appadurai, A. (1996). Modernity at large: Cultural Dimensions of Globalization. University of Minnesota Press.

- (2002). «Diversidad sostenible. La indivisibilidad de la cultura y el desarrollo». En Declaración Universal sobre la Diversidad Cultural. París: UNESCO.

Barreiro, B. (2011). La diversidad cultural en el Derecho Internacional. La Convención de la UNESCO. Madrid: Iustel.

BÉJAR, Helena (1990). El ámbito intimo. Madrid: Alianza.

Dumont, L. (1987). Ensayos sobre el individualismo. Madrid: Alianza.

Elias, N. (1987). El proceso de civilización. México: F. C. E.

García Canclini, N. (2010). Culturas hibridas. Estrategias para entrar en la modernidad. México: Paidós.

- (2009). Diferentes, desiguales y desconectados. Barcelona: Gedisa.

GeErTZ, C. (1996 [1986]). Los usos de la diversidad. Barcelona: Paidos.

Kymlicka, W. (1995). Multicultural Citizenship: A Liberal Theory of Minority Rights. New York: Oxford University Press.

LÉvi-Strauss, R. (2010 [1952]). «Raza e Historia» en Velasco, H. M. (comp.). Lecturas de Antropología Social y Cultural. La cultura y las culturas. Madrid: UNED, pp. 67-107.

LÉvi-Strauss, C. (1971). «Race et culture». Revue Internationale des Sciences Sociales vol. XX, N. ${ }^{4} 4$.

Moran, K., R. King, S. R., Carlson, T. J. (2001). «Biodiversity Prospecting: Lessons and Prospects». Annual Review of Anthropology, Vol. 30 (2001), pp. 505-526.

PretTy, J. et al. (2008). «How Do Biodiversity and Culture Intersect?» Plenary paper for Conference «Sustaining Cultural and Biological Diversity In a Rapidly Changing World: Lessons for Global Policy». Organized by American Museum of Natural History's Center for Biodiversity and Conservation, IUCN-The World Conser- 
vation Union/Theme on Culture and Conservation, and Terralingua. April 2-5th 2008.

Prieto, J. (2005). Excepción y diversidad cultural. Madrid: Fundación Alternativas.

Rostow. W. (1970 [1957]). El proceso de crecimiento económico. Madrid: Alianza.

Stenou, K. (2004). Unesco and the Issue of Cultural Diversity. Review and strategy 19462004. Paris: UNESCO.

- (2007). L'UNESCO et la question de la diversité culturelle. 1946-2007. Bilan et stratégies. Paris: UNESCO.

Stocking, G (1982). Race, Culture and Evolution. Chicago: The University of Chicago Press.

- (1987). Victorian Anthropology. Berkeley: The University of California Press.

Velasco, H. M.(2006). «La cultura noción moderna». Patrimonio cultural y derecho 10: 11-34.

UNEP, Posey, D. A. (ed.) (1999). Cultural and Spiritual Values of Biodiversity. London: Intermediate Technology Publications.

UNESCO\&UNP (2003). Cultural Diversity And Biodiversity For Sustainable Development. Roundtable held on 3 September 2002 in Johannesburg during the World Summit on Sustainable Development.

Wilson, E. O. (1999[1992]). The Diversity of Life. New York: W. W. Norton.

Recibido: 3/08/2012

Aprobado: 5/09/2012 